\title{
Kraakvorming in plastiese vars beton
}

Outeurs:

Daniël M Meyer

Riaan Combrinck

\section{Affiliasies:}

Universiteit van

Stellenbosch, Suid-Afrika

Korresponderende outeur: Riaan Combrinck

E-pos: rcom@sun.ac.za

\section{Datums: \\ Ontvang: $\quad 06 / 05 / 21$ \\ Aanvaar: $\quad 31 / 08 / 21$ \\ Gepubliseer: 20/10/21}

Hoe om hierdie artikel aan te haal:

Daniël M Meyer, Riaan Combrinck, Kraakvorming

in plastiese vars beton, Suid-Afrikaanse Tydskrif vir Natuurwetenskap en Tegnologie 40(1) (2021). https://doi.org/10.36303/ SATNT.2021.40.1.854

\section{Kopiereg:}

(C) 2021. Authors.

Licensee: Die SuidAfrikaanse Akademie vir Wetenskap en Kuns. Hierdie werk is onder die Creative Commons Attribution License gelisensieer.
Vars of plastiese beton beskryf die toestand van beton gedurende die eerste paar ure nadat die beton gegiet is. Vars beton het nog nie verhard nie en het ' $n$ baie lae treksterkte. Plastiese vervorming in vars beton kom voor in die vorm van plastiese versakking en plastiese krimp. Hierdie vervormings kan lei tot kraakvorming in beton in gebiede waar die beton versper word teen vrye volume verandering.

Die hoof meganisme wat plastiese krake veroorsaak is die opbou van kapillêre druk weens die verdamping van water uit die beton. Kapillêre druk verwys na die negatiewe druk, of suigkrag, wat ontstaan tussen die deeltjies van die beton wanneer die water verdamp uit die porieë van die beton. Dit word vererger deur ongunstige weersomstandighede wat die verdampingstempo verhoog.

Kraakvorming in vars beton is een van die hoof faktore wat bydra tot probleme met die duursaamheid en bruikbaarheid van betonstrukture. Die doel van hierdie studie is om krake te voorkom deur die verskynsel van kraakvorming, beide plastiese versakkings- en krimpkrake, beter te verstaan in terme van die bydraende meganismes, die interaksie tussen die twee kraaktipes en die omliggende klimaatstoestande.

In die studie word ' $n$ deeglike literatuurstudie gedoen oor volume verandering en kraakvorming in vars beton. 'n Gevallestudie word ook ondersoek om die oorsake van plastiese krake in 'n betonpad te identifiseer en vas te stel hoe die krake vorm.

Alhoewel die betonpad gegiet was van dieselfde mengsel en in dieselfde vorm, het slegs sekere segmente krake gevorm. Daar is vasgestel dat die variërende klimaatsomstandighede veroorsaak het dat sekere segmente kraak terwyl ander nie kraak nie. Daar is ook 'n definitiewe interaksie tussen die krake gevorm deur plastiese versakking en plastiese krimp.

Kraakvorming is die gevolg van beide plastiese versakking en plastiese krimp, alhoewel plastiese krimp hoofsaaklik die vergroting van die krake beïnvloed. Een van die belangrikste invloede wat die kwaliteit en duursaamheid beïnvloed, is die doeltreffendheid van die kuur van die beton, aangesien effektiewe kuring die opbou van kapillêre druk in die beton vertraag of voorkom, wat die risiko van plastiese krimpkrake verminder.

'n Deeglike kennis van hierdie verskynsels en die meganismes wat bydrae tot die kraakvorming, kan lei tot die voorkoming daarvan. Daar moet dus goeie voorsorgmaatreëls en konstruksiemetodes gevolg word wanneer beton gegiet word. Byvoorbeeld, die gevallestudie het gewys dat beton slegs gegiet moet word in weerstoestande wat nie 'n hoë potensiaal vir plastiese krimpkrake het nie. Die toepassing van die kennis kan die kwaliteit en duursaamheid van betonstrukture verbeter.

Sleutelwoorde: plastiese krimp, plastiese versakking, kapillêre druk, volume verandering

Cracking in plastic fresh concrete: Fresh or plastic concrete describes the condition of concrete during the first few hours after the concrete has been cast. Fresh concrete has not yet hardened and has a low tensile strength. Plastic deformation in fresh concrete occurs in the form of plastic settlement and plastic shrinkage. These deformations can lead to cracking in concrete in areas where the concrete is restrained from free volume change.

The main mechanism that causes plastic shrinkage cracks is the build-up of capillary pressure due to the evaporation of water from the concrete. Capillary pressure refers to the negative pressure, or suction force, that arises between the particles of the concrete when the water evaporates from the pores of the concrete. This is aggravated by adverse weather conditions that increases the evaporation rate.

Cracking in fresh concrete is one of the main factors contributing to problems with the durability and serviceability of concrete structures. The aim of this study is to better prevent cracks by improving the understanding of the phenomenon of crack formation, both plastic settlement and shrinkage cracks, in terms of the contributing mechanisms, the interaction between the two crack types and the surrounding climate conditions. 
In this study, a thorough literature study is done on volume change and crack formation in fresh concrete. A case study is also investigated to identify the causes of plastic cracks in a concrete road and to determine how the cracks formed.

Although the concrete road was cast from the same mixture and in the same shape, only certain segments formed cracks. It was established that the varying climate conditions caused some segments to crack while others did not crack. There is also a definite interaction between the cracks formed by plastic settlement and plastic shrinkage.

Cracking is the result of both plastic settlement and plastic shrinkage, although plastic shrinkage mainly affects the propagation of the cracks. One of the most important factors affecting the quality and durability is the efficiency of the curing of the concrete, as effective curing slows down or prevents the build-up of capillary pressure in the concrete, which reduces the risk of plastic shrinkage cracks.

Thorough knowledge of these phenomena and the mechanisms that contribute to the crack formation can lead to their prevention. Therefore, good precautions and construction methods must be adhered to when casting concrete. For example, the case study showed that concrete should only be cast in weather conditions that do not have a high potential for plastic shrinkage cracks. The application of this knowledge can improve the quality and durability of concrete structures.

Keywords: Plastic shrinkage, plastic settlement, capillary pressure, volume change

\section{Inleiding tot plastiese krake in beton}

Beton is een van die mees gebruikte materiale wêreldwyd. Dit word in byna alle konstruksie gebruik vanweë die hoë drukweerstand. Beton word dikwels saam met bewapeningstaal gebruik om 'n struktuur te versterk teen trek kragte. Die vars toestand van beton kan beskryf word as die plastiese of semi-vloeistof fase. Dit is wanneer die beton nog nie verhard het nie en nog in 'n vorm gemanipuleer kan word, wat gewoonlik duur vir die eerste paar uur nadat die beton gemeng en gegiet is. Plastiese krake kan vorm gedurende hierdie fase van beton en is dus een van die belangrikste fases vir die duursaamheid en kwaliteit van beton (ACI 231R, 2010; Qi, 2003; Ravina \& Shalon, 1968; Weyers et al., 1982).

Plastiese versakking is ' $\mathrm{n}$ eendimensionele vertikale vervorming wat in die beton voorkom. Die versakking vind plaas as gevolg van die soliede deeltjies in die beton wat afwaarts beweeg as gevolg van gravitasie en sodoende water na die oppervlak van die beton verplaas. Hierdie laag water staan bekend as bloeiwater (ASTM C232-20, 2020; Menzel, 1952; Menzel \& Woods, 1962). Sodra die bloeiwater van die betonoppervlak verdamp het, begin die water uit die porieë van die beton verdamp, wat veroorsaak dat ' $n$ driedimensionele krimp in die beton voorkom, bekend as plastiese krimp.

Gedurende die plastiese fase het die beton nie ' $n$ hoë treksterkte nie (ACI 231R, 2010; Combrinck et al., 2018b; Powers, 1968; Weyers et al., 1982). As gevolg van hierdie gebrek aan voldoende treksterkte, is dit moontlik dat die beton onder sekere omstandighede sal kraak (Cohen et al., 1990; Concrete Society, 1978; Ghourchian et al., 2018; Turton, 1978). Hierdie toestande het meestal te make met die omgewingstoestande, soos hoë temperatuur, lae relatiewe humiditeit en hoë windspoed rondom die beton (ACI R305, 1991; Cohen et al., 1990; Uno, 1998; Turton, 1978). Die tempo waarteen die verdamping plaasvind, die mate van beperking of inklemming van die beton se beweging, tesame met die treksterkte van die beton beïnvloed die hoeveelheid en grootte van krake wat kan voorkom. Die treksterkte wissel na gelang van die bestanddele van die betonmengsel. Die krake dien as weë vir die binnedring van skadelike stowwe wat die duursaamheid en lewensduur van die betonstruktuur in gevaar stel (Concrete Society, 1978; Ravina \& Shalon, 1968; Turton, 1978).

'n Kombinasie of interaksie tussen plastiese krimpkrake en plastiese versakkingskrake kan egter ook voorkom. Plastiese versakkingskrake vorm gewoonlik eerste, gevolg deur plastiese krimpkrake (Combrinck et al., 2018a; Kwak et al., 2010; Neville, 2011). Plastiese versakkingskrake kan geïdentifiseer word as veelvuldige trekkrake sowel as krake onder die oppervlak wat deur skuifspanning veroorsaak word. Plastiese krimpkrake illustreer daarenteen 'n goed gedefinieerde enkele kraakpatroon wat skielik en dikwels deur die hele deursnit van die beton vorm (Boshoff \& Combrinck, 2013; Concrete Society, 1978; Qi, 2003). Struktuurelemente met groot blootgestelde oppervlaktes is meer geneig tot plastiese krimping soos byvoorbeeld 'n brugdek, betonvloer en blad of plaveisel elemente (ACI 305, 1991; Lerch, 1955; Ravina \& Shalon, 1968; Uno, 1998).

Kraakvorming is die gevolg van skielike verandering in die klimaat rondom die beton. Hierdie klimaatverandering is soms baie subtiel en kan eenders voorkom of voel van dag tot dag. Kontrakteurs wat beton giet is dus nie altyd bewus van hierdie veranderinge in klimaatstoestande nie.

In hierdie studie word 'n oorsig van plastiese vervorming en krake wat plaasvind in beton bespreek deur fundamenteel na literatuur te verwys, gevolg deur'n gevallestudie waar die beton gekraak het. In die gevallestudie word die oorsaak van die krake in die betonpad ondersoek deur te kyk na die mengselontwerp, tyd wanneer die krake gevorm het, klimaatstoestande, asook die afwerking en gietprosedures gevolg deur die kontrakteurs. 


\section{Volume verandering in vars beton}

Krake in vars beton wat veroorsaak word deur 'n volume verandering kan moontlik die strukturele integriteit en duursaamheid van die betonelement benadeel. Selfs al is hierdie krake nie altyd struktureel problematies nie, is dit onooglik. Oor 'n lang periode verhoog hierdie krake ook die waarskynlikheid dat skadelike stowwe die beton sal binnedring en dit verswak, wat die bruikbaarheid van die elemente sal verminder (Cohen et al., 1990; Concrete Society, 1978; Weyers et al., 1982).

\section{Plastiese versakking}

Die tipe volumeverandering wat plaasvind hang af van die ouderdom en die toestand van die beton. Die versakking begin sodra die beton geplaas is en vind plaas voor die aanvang van plastiese krimp en kombineer later met die gevolge van krimp wat veroorsaak word deur verdamping. Die versakking kan meganies gestop word as gevolg van die soliede beton deeltjies wat in aanraking kom met mekaar, of as gevolg van die hidrasie en verharding van die beton wat verhinder dat die versakking plaasvind.

Krake sal vorm as die versakking van die soliede deeltiies beperk word. Sulke beperkings kan veroorsaak word deur staalbewapening in die beton of deur 'n dimensionele diepte verandering in die beton. Hierdie krake staan bekend as plastiese versakkingskrake (Menzel, 1952; Menzel \& Woods, 1962). Die diameter, spasiëring en betondekking van bewapeningsstawe het egter ook 'n invloed op die vorming van plastiese versakkingskrake, en kan kraakvorming beperk of selfs verhoed (Concrete Society, 1978, ACI R305, 1991). Kraakvorming kan beperk of voorkom word deur meer stawe met 'n kleiner diameter te gebruik, sowel as om die betondekking so groot as moontlik te maak. Figuur 1 toon die vorming van plastiese versakkingskrake aan: (a) betonblad na die plasing van die beton wat illustreer dat versakking deur staalbewapening beperk word; (b) plastiese versakkingskrake vorm bo die bewapening en leemtes onder die bewapening; (c) betonblad wat die beperking illustreer wat veroorsaak word deur ' $n$ verandering in die deursnee-diepte van die blad; (d) vorming van versakkingskrake as gevolg van verandering in die diepte van die blad. Die meganisme wat lei tot die vorming van versakkingskrake is differensiële versakking; hierdie krake vorm nie waar uniformige versakking plaasvind nie. Vanweë die direkte verband tussen die plastiese krake en die bloeiwater van die beton, sal die vermindering van die bloeipotensiaal van die beton die risiko van plastiese krake verminder (Powers, 1968; Owens, 2009).

\section{Plastiese krimp}

Krimp wat in beton voorkom, hou meestal verband met die beweging van vog uit beton (Lerch, 1957; Owens, 2009; Turton, 1978). Plastiese krimp kom voor as gevolg van porie-waterwatverdampuit diebeton. Dieklimaatstoestand sowel as die betonmengsel-eienskappe kan die tempo van verdamping verhoog of verlaag, met plastiese krimp wat eers begin sodra al die bloeiwater op die beton oppervlakte

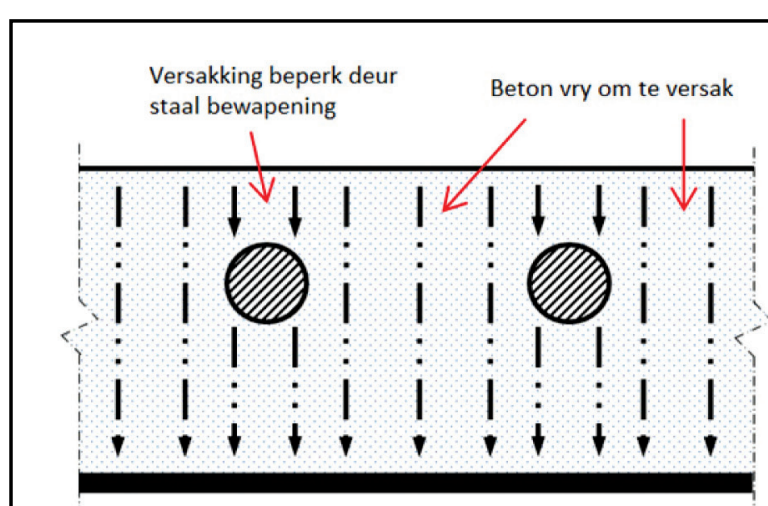

a)

Beton in vlak seksies versak minder as in diep seksies

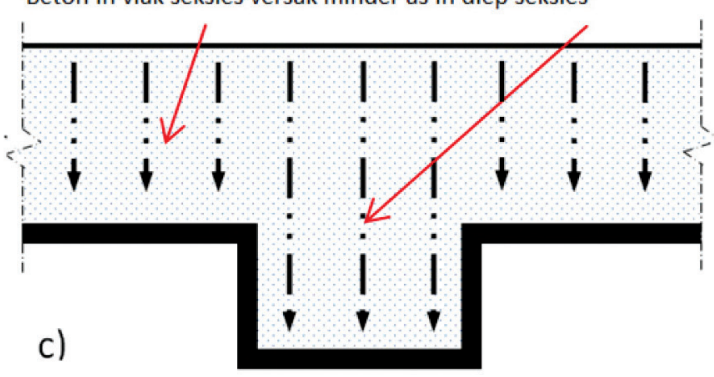

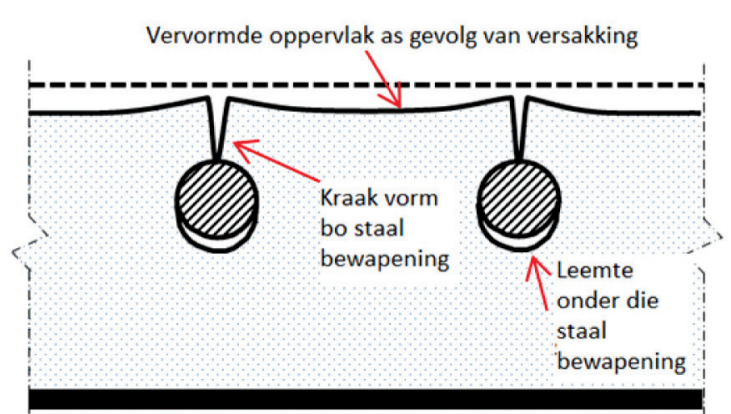

b)

Vervormde oppervlak as gevolg van versakking

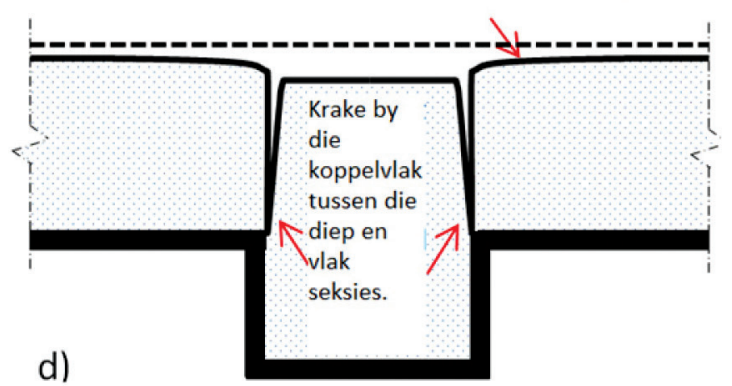

FIGUUR 1: Vorming van plastiese versakkingskrake soos getoon in Combrinck (2016) met soortgelyke inligting in Powers (1968), Concrete Society (1978), Turton (1978), Weyers et al. (1982). 
verdamp het. Oor die algemeen, en veral in Suid-Afrika se klimaatstoestande, sal 'n hoër verdampingstempo lei tot meer plastiese krimp.

Uno (1998) het 'n vergelyking (vergelyking 1) voorgestel om die verdampingstempo te skat op grond van sekere klimaatstoestande. Hierdie vergelyking was hoofsaaklik gebaseer op die modelle wat Menzel (1954), Harbeck et al. (1954) en Kohler et al. 1955) aangebied het. Uno verwys ook na die vergelykings wat deur Tetens (1930) voorgestel is, en waarna Murray (1967), Dilley (1968) en Mills (1975) verwys, wat met temperatuur en dampdruk verband hou. Die vergelyking neem verskillende klimaatstoestande in die omliggende mikroklimaat van die beton in ag. Die windspoed, lugtemperatuur, relatiewe humiditeit, sowel as die betontemperatuur dra by tot die verdampingstempo. Die vergelyking kan as volg uitgedruk word:

$$
\mathrm{ER}=5 \times 10^{-6}(\mathrm{~V}+4)\left[\left(\mathrm{T}_{\mathrm{c}}+18\right)^{2.5}-\mathrm{r}\left(\mathrm{T}_{\mathrm{a}}+18\right)^{2.5}\right]
$$

Waar:

$$
\begin{aligned}
& \mathrm{ER}=\text { Verdampingstempo }\left[\mathrm{kg} / \mathrm{m}^{2} / \mathrm{h}\right] \\
& \mathrm{V}=\text { Windspoed }[\mathrm{km} / \mathrm{h}] \\
& \mathrm{T}_{\mathrm{c}}=\text { Betontemperatuur }\left[{ }^{\circ} \mathrm{C}\right] \\
& \mathrm{r}=\text { Relatiewe humiditeit }[\%] \\
& \mathrm{T}_{\mathrm{a}}=\text { Lugtemperatuur }\left[{ }^{\circ} \mathrm{C}\right]
\end{aligned}
$$

Plastiese krimp is 'n driedimensionele volume verandering. Plastiese krimpkrake is een van die vroegste krake wat in beton ontwikkel en kan uitgeken word aan 'n enkel kraakpatroon (ACI 231R, 2010; Concrete Society, 1978; Ravina \& Shalon, 1968). As die beton staalbewapening bevat, is die krake oor die algemeen in lyn met die bewapeningspatroon. Plastiese krimpkrake word veroorsaak deur 'n negatiewe druk of suigkrag in die poriestelsel van die beton. Hierdie meganisme staan bekend as kapillêre druk. Sodra die poriewater begin verdamp, begin die negatiewe kapillêre drukgradiënt aansienlik toeneem (Cohen et al., 1990; Slowik et al., 2008; Wittmann, 1976). By 'n sekere druk dring lug die beton in, wat lei tot 'n lokalisering van die spanning en vorm krake in die vroeë ouderdom van die beton (Slowik et al., 2008; Wittmann, 1976). Die druk word veroorsaak deur die verdamping van poriewater uit die beton. Omdat die klimaatstoestande die verdampingstempo beïnvloed, beïnvloed dit ook die kapillêre druk.

Aanvanklik is die spasies tussen die soliede deeltjies byna heeltemal gevul met water. As gevolg van verdamping verminder die dikte van die waterlaag op die beton totdat daar nie meer water op die oppervlakte is nie. Dit vind plaas wanneer die verdampingstempo die bloeitempo van die beton oorskry. Die gevolge van verdamping en krimp wat lei tot kraakvorming kom meer voor in blad-elemente waar die oppervlakte wat aan verdamping blootgestel word, baie groot is (Kraai, 1985). As gevolg van die verdamping vorm water meniskusse tussen die soliede deeltjies en veroorsaak dit 'n negatiewe druk of suigkrag in die poriewater. Die beton deeltjies beweeg dus nader aan mekaar en krimp die beton (Cohen et al., 1990; Wittmann, 1976). Die voortdurende verdamping veroorsaak ' $n$ deurlopende inkrimping en 'n toename in die negatiewe kapillêre druk (Slowik et al., 2008). Volgens studies bereik beton sy laagste trekkapasiteit op 'n ouderdom naby aan die aanvanklike settyd van die beton (Boshoff \& Combrinck, 2013; Slowik et al., 2008). Die opbou van kapillêre druk en deurbraakdruk word geïllustreer in Figuur 2. Deurbraak vind plaas wanneer die poriee in die beton nie meer heeltemal met water gevul is nie (Slowik et al., 2008; Wittmann, 1976). Die plastiese krimp van die beton begin onmiddellik nadat die negatiewe porie-druk begin ontwikkel (Boshoff \& Combrinck, 2013; Cohen et al., 1990).

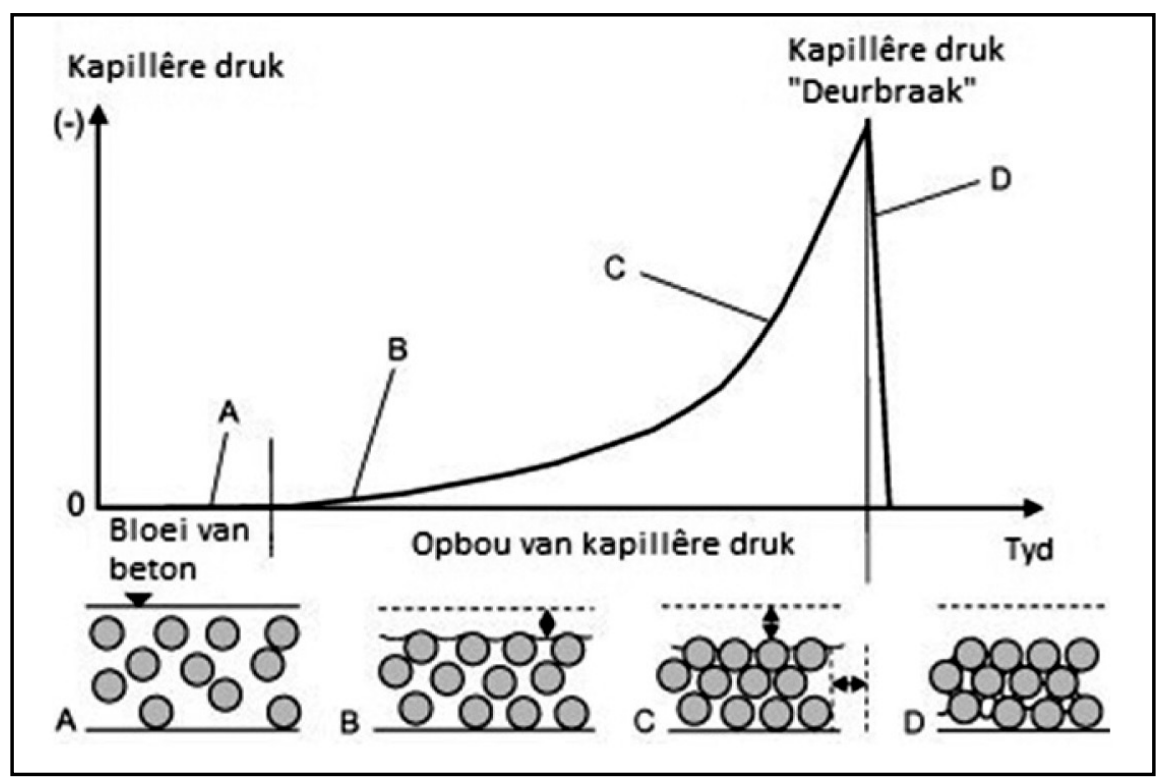

FIGUUR 2: Opbou van negatiewe kapillêre druk (aangepas van Slowik et al., 2008). 
Die beton vorm slegs krake as vrye beweging beperk word. Hierdie beperkings sluit in bewapeningsstawe, elementuitleg, vervormingsgradiënt (wanneer een deel van die beton minder krimp as ' $n$ ander as gevolg van differensiële uitdroging, temperatuur of waterverlies na die grondlaag) en wrywing van die bekisting of grondlaag.

Studies (Boshoff \& Combrinck, 2013; Combrinck, 2011; Turcry \& Loukili, 2006) toon aan dat plastiese krimpkrake waargeneem word vanaf ouderdomme na aan die aanvanklike settyd van die beton. Daarna sal die krake teen 'n hoër tempo vergroot en later geleidelik stabiliseer wanneer die beton se finale settyd bereik word. Hierdie krake kan nog steeds groei na die finale settyd, maar dan word dit meestal toegeskryf aan drogingskrimping en temperatuurvariasies (Neville, 2011; Powers, 1968).

Daar word egter opgemerk dat die verdampingstempo van water nie die enigste bydraende faktor tot die opbou van die kapillêre druk is nie, maar die grootte en verspreiding van die deeltjies of korrels in die betonmengsel het ook 'n effek. Hoe kleiner die spasies tussen die deeltjies van die beton is, hoe steiler en vinniger bou die negatiewe kapillêre druk op vir 'n gegewe verdampingstempo (Slowik et al., 2008).

\section{Kombinasie van plastiese krake}

Alhoewel plastiese versakking en plastiese krimp goed gedefinieer is, bly daar 'n komplekse wisselwerking tussen hierdie twee volumeveranderings wat krake betref (Kwak et al. 2010; Neville, 2011). Die interaksie tussen die twee kan lei tot onvoorspelbare kraakvorming en gedrag. Alhoewel versakking en krimp afsonderlik kan voorkom is dit selde die geval as daar na blad elemente verwys word, veral waar bewapeningstaal teenwoordig is. Volgens Kwak et al. (2010), is ongeveer $40 \%$ van die plastiese krimpkrake die gevolge van plastiese versakkingskrake.

Dit is moeilik om duidelik te onderskei tussen die twee soorte krake as gevolg van die nabyheid en selfs oorvleueling van die tydperk waarin die krake plaasvind. Plastiese versakking kom aanvanklik voor en skep 'n swak area in die beton waar plastiese krimp sal volg en krake kan ontwikkel. Die grootte van die versakkingskrake beïnvloed die krimpkrake wat ontstaan. Hoe erger die versakkingskrake is, hoe erger word die krimpkrake (Combrinck et al., 2018a).

Figuur 3 illustreer die moontlike kraakgedrag wat onder sekere omstandighede verwag kan word. Onder toestande waar daar ' $n$ matige tot hoë potensiaal is vir plastiese krimp en versakking, kan daar ' $\mathrm{n}$ kombinasie van hierdie twee soorte krake voorkom.

\section{Kraak voorkoming}

Dit is belangrik om die hoeveelheid en grootte van krake in die vroeë ouderdom te minimaliseer weens strukturele en estetiese redes. Die krake verlaag die styfheid van 'n struktuur en vererger duursaamheidskwessies op die langtermyn, soos korrosie van die bewapening (Cohen et

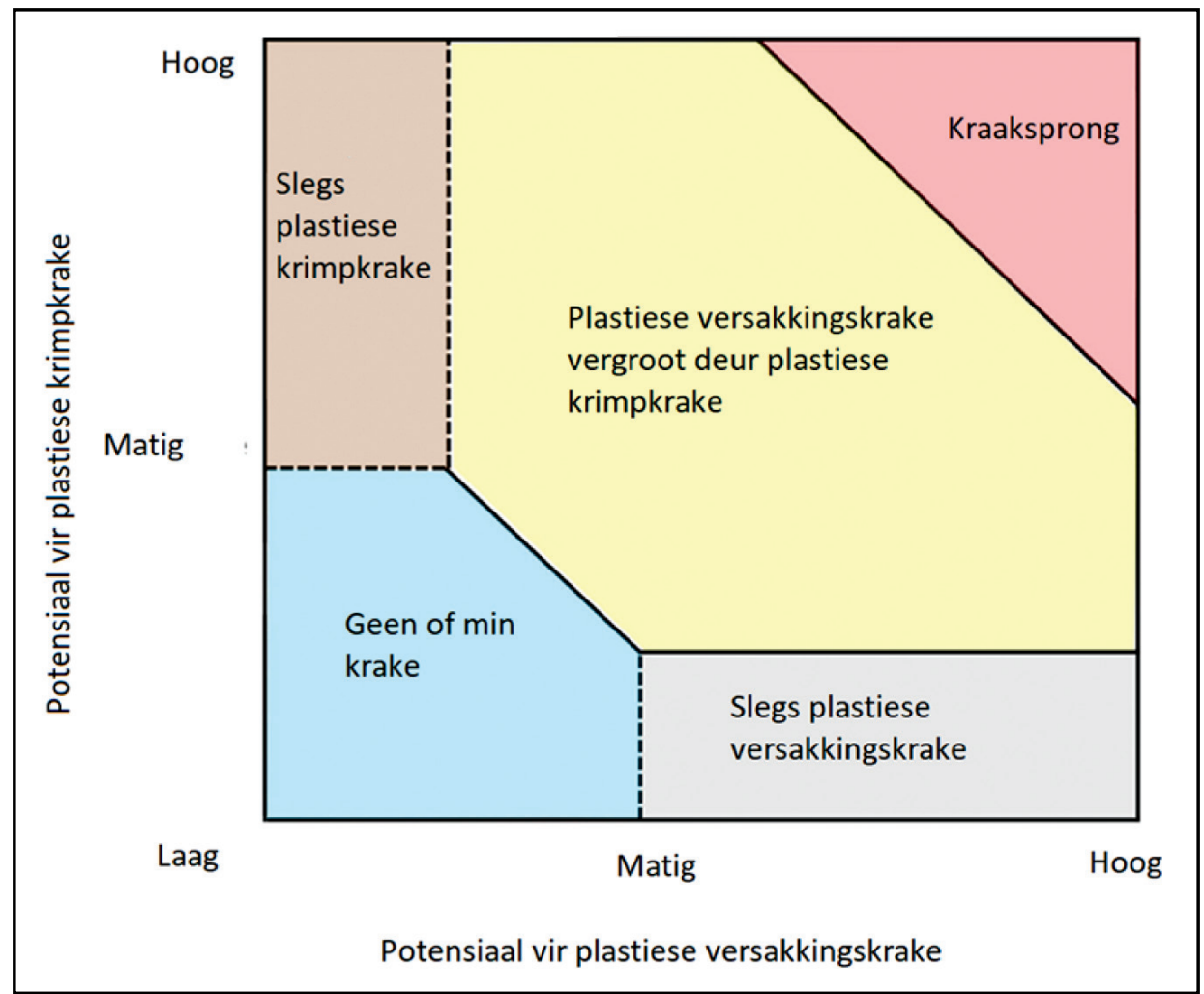

FIGUUR 3: Verskillende potensiële kraakgedrag as die gekombineerde effek van plastiese afsakking en plastiese krimping oorweeg word (aangepas van Combrinck et al., 2018a). 
al., 1990; Concrete Society, 1978; Turton, 1978; Weyers et al., 1982). Dit skep strukturele defekte omdat die beton en die bewapening verband verloor weens openinge wat onder die bewapening vorm. Die krake vorm deurweë vir ongewenste stowwe soos water, suurstof, chloriede en koolstofdioksied $\left(\mathrm{CO}_{2}\right)$. Dit skep ook swak punte vir verdere krake om na die plastiese fase te ontwikkel en te groei. Termiese, chemiese en droogkrimping kan verdere groei van die krake veroorsaak na afloop van die plastiese toestand van die beton (Combrinck, 2016; Owens, 2009; Powers, 1968). Hierdie krake is ook onooglik en skep 'n swak afwerking van die blootgestelde aansigte van beton.

Van die mees algemene en effektiewe metodes om plastiese krake in beton te voorkom is om effektiewe kuringsmetodes toe te pas. Kuring is ' $n$ proses waarmee die beton beskerm word teen vogverlies wat benodig word vir hidrasie. Hierdie vogverlies kan voorkom word deur die betonoppervlakte nat te hou met 'n misbesproeiing, 'n chemiese kuurmiddel aan te wend of die oppervlak te bedek met nat sand of plastiek (Uno, 1998; NRMCA, 2006). Dit is egter baie belangrik dat die chemiese kuurmiddel aangewend moet word volgens die produk spesifikasies. Indien die kuurmiddel nie reg aangewend word nie kan dit lei tot 'n laer kwaliteit oppervlakte met defekte soos skilfering van die oppervlakte.

Om die risiko van plastiese krake te verminder, moet die poriedruk onder die deurbraakdruk gehou word. Om dit te bereik, is die fokus meestal om die verdampingstempo so laag as moontlik te hou. 'n Riglyn sou wees om hierdie waarde onder $0.5 \mathrm{~kg} / \mathrm{m}^{2} / \mathrm{h}$ te hou (ACI305, 1991; Australian Pre-Mixed Concrete Association, 1995). Om krimping te voorkom, moet die verdampingstempo egter onder die bloeitempo van die spesifieke beton gehou word. Die tyd wanneer al die bloeiwater verdamp het, is van kritieke belang (Cohen et al., 1990). As die laag bloeiwater voor die betonverharding verdwyn, kan die krake erger wees. Dus sou minder krake voorkom as die verwydering van bloeiwater vertraag word (Cohen et al., 1990).

Die betonmengsel kan aangepas word om die potensiaal vir plastiese vervorming in beton te verlaag. Die verandering van die stofinhoud het'n teenstrydige effek op die versakking en die krimp van die beton. Deur die stofinhoud (partikels kleiner as 75 mikrometer) van die sand te verhoog word die bloeipotensiaal van die beton verlaag aangesien die kleiner partikels die beweeg van die water na die oppervlakte vertraag. Die kleiner bloeipotensiaal verlaag die risiko vir plastiese versakkingskrake (Wontanakitcharoen, 2005). Die toevoeging van die fynstof van byvoorbeeld ' $n$ vergruisde sand is veral effektief om die versakking te verminder.

Die ekstra fynstof verhoog egter die potensiaal vir plastiese krimpkrake deur die bloei- potensiaal te verlaag en die opbou van die kapillêre druk te verhoog (Wontanakitcharoen, 2005). Aangesien plastiese versakkingskrake hoofsaaklik plaasvind as gevolg van differensiële versakking van beton, sal dit meer voordelig wees om die betonmengsel aan te pas om die risiko van plastiese krimpkrake te verlaag.

Plastiese krimp kan ook verminder word deur ys by die mengwater te voeg, en sodoende die betontemperatuur, asook die verdampingtempo te verlaag (ACI R305, 1991).

Een van die maklikste maniere om krake te verminder of te voorkom deur die mengselontwerp aan te pas, is om die sementpasta-inhoud te verminder en die hoeveelheid klip in die beton te verhoog. Alhoewel hierdie metode nie altyd prakties moontlik is nie, verminder dit veral die effek van droog - en chemiese krimp (ACI 231R, 2010).

Die gebruik van interne kuurmiddels en die toevoeging van chemiese produkte, soos krimp-reduseermiddels of uitbreidende bymiddels, is ook geskik om krake te voorkom. ' $n$ Meer gevorderde metode om krake te beheer is om ' $n$ lae volume polimeriese mikrovesels by die beton te voeg om die groei van die krake te beperk (ACI 231R, 2010).

Moelich \& Combrinck (2020) het navorsing gedoen oor die voorkoming van vroeë ouderdom krimpkrake in beton vir spesifieke gebiede in Suid-Afrika deur weerpatrone te analiseer en algemene tendense te identifiseer vir daardie gebied. Die voorgestelde metode dui daarop dat spesifieke kuringsmetodes deur die loop van die jaar gebruik moet word, terwyl addisionele voorkomingsmetodes in die somermaande ingestel moet word. Die studie toon ook aan dat hierdie addisionele kuringsmetodes vermy kan word deur beton te giet in klimaatsomstandighede wat 'n lae verdampingstempo het.

\section{Gevallestudie oor plastiese krake in beton Oorsig}

In verskeie konstruksie projekte word betonblaaie, met groot oppervlaktes, blootgestel aan ongunstige weerstoestande wat kan lei tot die vorming van plastiese krake. 'n Gevallestudie is gedoen oor krake wat gevorm het in 'n betonpad in die Wes-Kaap. In die gevallestudie is die oorsaak van die krake in die betonpad ondersoek deur te kyk na die mengselontwerp, tyd wanneer die krake gevorm het, klimaatstoestande, asook die afwerking en gietprosedures wat gevolg was. Die krake word ondersoek deur te kyk na vier opeenvolgende dae (Dae 1 tot 4) se klimaat. Beton was gegiet op Dag 2 en Dag 4, maar slegs op een van die dae (Dag 2) het krake gevorm.

\section{Uitleg van die betonpad}

Die betonpad waar die krake voorgekom het, is ' $n$ pad wat ongeveer 70 meter lank is, 3.9 meter breed en 0.25 meter dik. Die pad bevat ongeveer $68 \mathrm{~m}^{3}$ beton. Die beton is versterk deur staal bewapening in die middel van die beton 
te plaas. Daar is Y12 stawe in die dwarsrigting geplaas, terwyl Y20 stawe bo-op die Y12 stawe in die langsrigting gebind is. Die staalbewapening is gespasieer teen $170 \mathrm{~mm}$ tussen die stawe in beide rigtings. Figuur 4 dui die uitleg van betonpad aan.

\section{Gietprosedure}

Die gietprosedure vir Dag 2 en Dag 4 was dieselfde. Op die dag wat die krake gevorm het (Dag 2), was die beton uit 10 verskillende trokke gegiet tussen 08:50 en 13:30. Die beton was direk vanuit die trokke gegiet en gekompakteer deur van 'n naaldvibreerder gebruik te maak. Die beton was verder gelyk gemaak en afgewerk deur van 'n reihout gebruik te maak. Nadat die beton afgewerk was, was dit gevee om dit die gewenste growwe afwerking te gee. Die beton was gekuur deur 'n chemiese mengel, wat spesifiek ontwerp is vir die kuur van beton, op die oppervlak van die beton te sit. Die kuurmiddel was ongeveer 60 minute na die giet van die beton aangewend. Tabel 1 toon inligting rakende die vragmotors, giettye, gietlengtes en krake wat gevorm het. Hierdie inligting is vir die dag wat die krake gevorm het.

\section{Mengselontwerp}

Die mengselontwerp vir die beton is opgesom in Tabel 2 . Weens intellektuele eiendoms- vereistes mag die presiese proporsies van die mengsel nie gepubliseer word nie. Die beton het 'n uitsakking van $100 \mathrm{~mm}$ en ' $\mathrm{n}$ water tot binder verhouding van net bo 0.5 . Die stofinhoud (partikels kleiner as 75 mikrometer) van die klip en die sand voldoen aan die vereistes van SANS 1083 (2002). Die stofinhoud van die klip en sand het wel effens gewissel van monster tot monster.

TABEL 2: Mengselontwerp van die beton.

\begin{tabular}{l|c|c}
\hline Materiaal & $\begin{array}{c}\text { Relatiewe } \\
\text { digtheid }\end{array}$ & $\begin{array}{c}\text { Hoeveelheid } \\
\text { (in kg per } \text { }^{3} \text { ) }\end{array}$ \\
\hline Water & 1.00 & $170-180$ \\
Sement (CEM II 52.5N) & 3.10 & $275-285$ \\
Slagment en pigment & 4.03 & $90-100$ \\
Lignosulfaat Plastiseerder & 1.20 & $1.5-2.0$ \\
Hornfels klip (14 en 28 mm) & 2.74 & $1050-1150$ \\
Sand (Vergruiser stof en Duinsand) & 2.67 & $750-850$ \\
\hline
\end{tabular}

\section{Klimaatstoestande}

Figuur 5 toon die klimaatstoestande aan vir die vier dae insluitend beide dae waarop die beton gegiet was sowel as die dag voor en tussen die giet dae in terme van die windspoed, relatiewe humiditeit en lugtemperatuur, asook die wolkbedekking en wind rigting. Die inligting is verkry vanaf ' $n$ betroubare weerstasie naby die terrein waar die beton gegiet was. Die figuur wys dat daar op Dag 2 (giet dag) 'n noemenswaardige afname in die relatiewe humiditeit plaasgevind het (met meer as $50 \%$ ) en dat die windspoed met ongeveer $20 \mathrm{~km} / \mathrm{h}$ toegeneem het vanaf 08:00 tot 12:00.

Op Dag 4 was daar ' $\mathrm{n}$ afname in die windspoed van ongeveer $13 \mathrm{~km} / \mathrm{h}$ tussen 05:00 en 09:00, gevolg deur 'n $7 \mathrm{~km} / \mathrm{h}$ toename tot en met 11:00. Die afname in die windspoed was gunstig vir die giet van beton, terwyl die

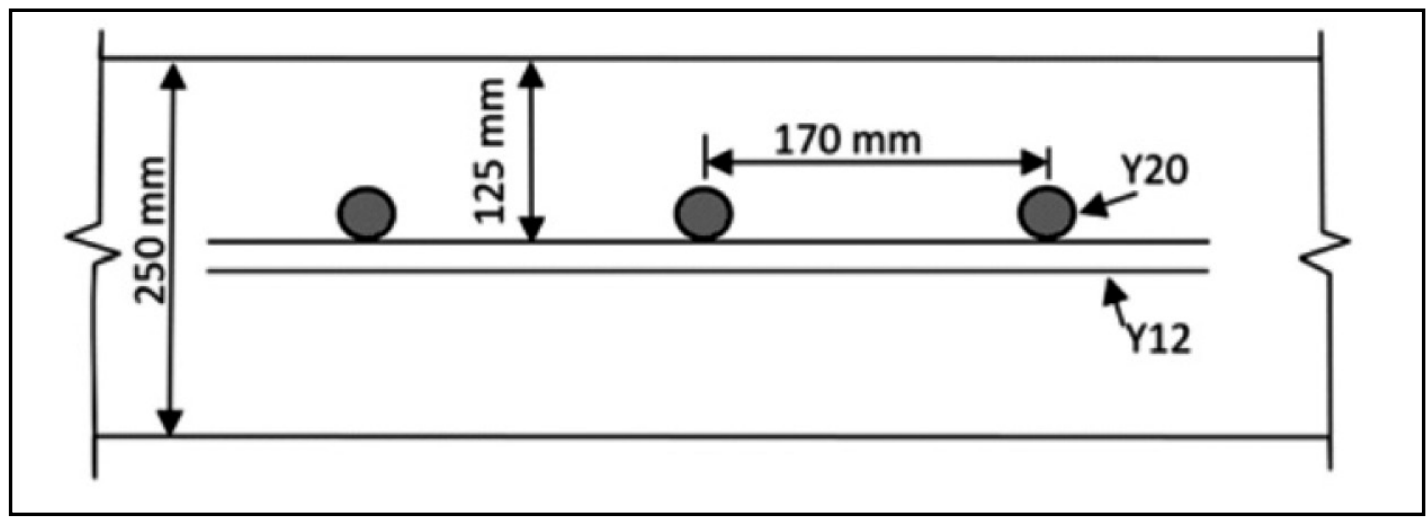

FIGUUR 4: Snitaansig deur die betonpad.

TABEL 1: Inligting rakende die vragmotors, giettye, gietlengtes en krake wat gevorm het.

\begin{tabular}{c|c|c|c|c|c}
\hline \multirow{2}{*}{$\begin{array}{c}\text { Vragmotor } \\
\text { nommer }\end{array}$} & $\begin{array}{c}\text { Vragmotor } \\
\text { volume }\left[\mathrm{m}^{3}\right]\end{array}$ & $\begin{array}{c}\text { Ontlaai } \\
\text { begin tyd }\end{array}$ & Begin & Einde & \multirow{2}{*}{ Kraakvorming } \\
\cline { 4 - 5 } & 6 & $8: 49$ & 0 & 7 & Geen \\
2 & 6 & $9: 16$ & 7 & 14 & Geen \\
3 & 8 & $9: 30$ & 14 & 23 & Geen \\
4 & 8 & $9: 45$ & 23 & 28 & Geen \\
5 & 6 & $10: 07$ & 28 & 34 & Ja, klein krake aan die einde \\
6 & 6 & $10: 59$ & 34 & 40.5 & Ja, deurgaans \\
7 & 8 & $11: 12$ & 40.5 & 49 & Ja, deurgaans \\
8 & 8 & $11: 25$ & 49 & 57 & Ja, deurgaans \\
9 & 8 & $12: 10$ & 57 & 65 & Ja, deurgaans \\
10 & 6 & $12: 51$ & 65 & 70.7 & Ja, klein krake aan die begin \\
\hline
\end{tabular}


toename in die windspoed nie noemenswaardig was nie. Daar was ook ' $n$ afname in die relatiewe humiditeit (ongeveer 20\%), alhoewel dit baie minder en teen 'n stadiger tempo plaasgevind het as op Dag 2.

Die aanwending van ' $n$ kuurmiddel is veronderstel om die verlies van vog uit die beton te verminder, en sodoende die potensiaal vir plastiese krake te verlaag. 'n Kuurmiddel was op soortgelyke wyse aangewend op beide dae wat beton gegiet was. Daar kan dus aanvaar word dat die kuurmiddel die gevolge van plastiese krake sou versag deur die verdamping te verminder. Die kuurmiddel was wel nie in staat om die krake te voorkom op Dag 2 nie. Daar is verder geen inligting beskikbaar vir die gevallestudie oor of die kuurmiddel die verdamping wel verminder het en met hoeveel nie. Om die redes is daar besluit om nie die effek van die kuurmiddel in ag te neem nie.

Die verandering in klimaatstoestande soos getoon in Figuur 5 het 'n groot impak op die verdampingstempo van die water vanaf die betonoppervlakte (ACI 305, 1991; Lerch, 1955; Soroka \& Ravina, 1998). Daar is bewys dat die son die temperatuur van die beton se oppervlak met meer as $5^{\circ} \mathrm{C}$ kan verhoog op 'n normale matige dag met 'n temperatuur van $20^{\circ} \mathrm{C}$ (Van Zyl, 2021). Aangesien dit slegs matig bewolk was gedurende die tye wat die beton gegiet was op Dag 2 en Dag 4, kan daar aangeneem word dat die beton se temperatuur ongeveer $5^{\circ} \mathrm{C}$ meer was as die lugtemperatuur. Figuur 6 dui die verdampingstempo aan, soos bereken met Uno (1998) se vergelyking, indien die beton se temperatuur gelyk was aan die lugtemperatuur, asook indien die beton se temperatuur $5^{\circ} \mathrm{C}$ meer as die lugtemperatuur was. Op Dag 2 was die verdampingstempo baie laag tot en met 08:00, ongeveer $0.2 \mathrm{~kg} / \mathrm{m}^{2} / \mathrm{h}$, maar het skielik gestyg na 08:00 en gegaan tot by 'n maksimum van $0.9 \mathrm{~kg} / \mathrm{m}^{2} / \mathrm{h}$ (beton temperatuur = lug temperatuur) en 1.5 $\mathrm{kg} / \mathrm{m}^{2} / \mathrm{h}$ (beton temperatuur $5^{\circ} \mathrm{C}>$ as lug temperatuur). Die verdampingstempo op Dag 4 was baie laer met ' $n$ maksimum van $0.24 \mathrm{~kg} / \mathrm{m}^{2} / \mathrm{h}$ (beton temperatuur = lug temperatuur) en $0.61 \mathrm{~kg} / \mathrm{m}^{2} / \mathrm{h}$ (beton temperatuur $5^{\circ} \mathrm{C}>$ as lug temperatuur). ' $\mathrm{n}$ Verdampingstempo bo $1 \mathrm{~kg} / \mathrm{m}^{2} / \mathrm{h}$ is uiters ongunstig en sal plastiese krimpkrake vorm indien daar nie addisionele kuringsmetodes in plek gestel word nie (ACI 305, 1991; Carden \& Ramey, 1999; Uno,1998). Verskeie studies (ACI 305, 1991; Australian Pre-Mixed Concrete Association, 1995; Carden \& Ramey, 1999, Boshoff \& Combrinck, 2013) noem as riglyn dat die verdampingstempo onder $0.5 \mathrm{~kg} / \mathrm{m}^{2} / \mathrm{h}$ moet wees om krake te voorkom. Beide die 0.9 en $1.5 \mathrm{~kg} / \mathrm{m}^{2} / \mathrm{h}$ verdampingstempo's op Dag 2 was dus uiters geskik vir die vorm van plastiese krimp krake. Alhoewel die verdampingstempo op Dag 4 effens hoër as $0.5 \mathrm{~kg} / \mathrm{m}^{2} / \mathrm{h}$ was (beton temperatuur $5^{\circ} \mathrm{C}>$ as lug temperatuur), was daar geen skielike veranderinge in die tempo nie en het daar dus geen krake gevorm nie.

Figure 5 en 6 toon dat alhoewel die gemiddelde temperatuur op Dag 4 hoër was, en die windspoed hoër was op Dag 3, was die verdampingstempo op Dae 1, 3 en 4 baie laer as op Dag 2. Dit is weens die meer konstante weerstoestande op Dae 1, 3 en 4 in vergelyking met Dag 2. Op Dag 2 was daar' $n$ skielike afname in relatiewe humiditeit van meer as $40 \%$ in 4 ure sowel as ' $n$ toename in windspoed van meer as $20 \mathrm{~km} / \mathrm{h}$ in 4 ure van 08:00 die oggend. Beide die veranderinge het die verdampingstempo aansienlik verhoog

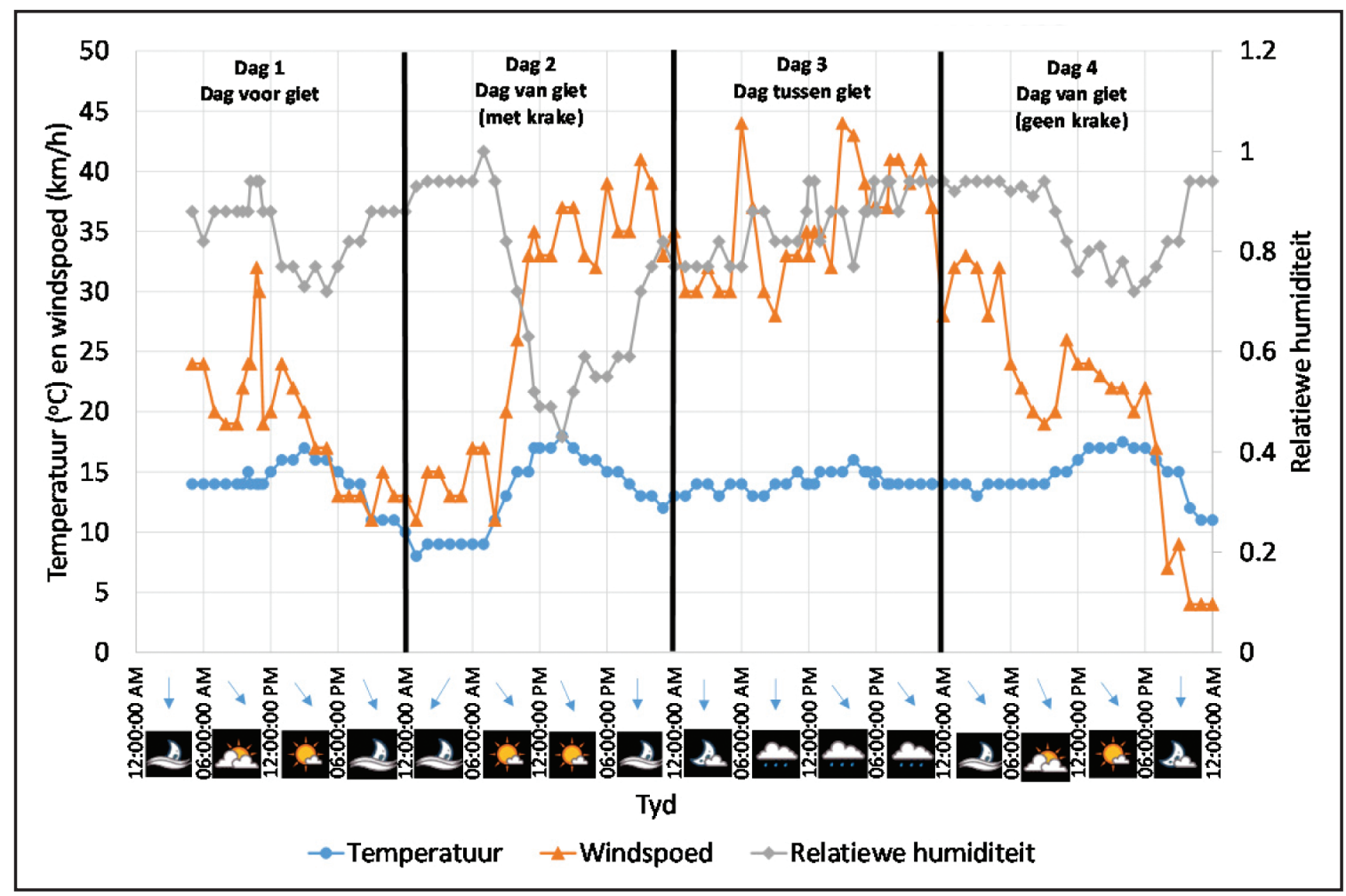

FIGUUR 5: Klimaatstoestande van Dae 1 tot 4 
en gelei tot die vorming van krake. Die verandering in veral relatiewe humiditeit (wat ook verband hou met die toename in lugtemperatuur) kan gesien word as onverwags en nie iets wat maklik op 'n konstruksie terrien opgemerk sal word nie. Op die oog af, sowel as uit die persepsie van persone op 'n konstruksie terrein, sou Dag 3 as die meer gevaarlike dag vir plastiese krake beskou kon word, veral as net na die windspoed gekyk word soos in Figuur 5. Dit is egter die impak van die skielike verandering van Dag 2 wat meer gevaar inhou vir krake en die voorkoming daarvan, aangesien die weerstoestande nie konstant was nie en dus meer onvoorspelbaar was en moeilik om te akkommodeer.

\section{Waargenome plastiese krake in die beton}

Figuur 7 dui die tipiese kraakpatroon aan soos dit waargeneem was op die oppervlakte van die beton. Die krake was in die langsrigting van die betonpad en stem ooreen met die spasiëring van die Y20 staalbewapening. Die kraakwydte het gewissel tussen 0.3 en $1.2 \mathrm{~mm}$ op die oppervlakte van die beton.

Figuur 8 wys die kraak onder die oppervlak soos dit gesien kan word van twee silinders wat uit die betonpad geboor was. Hieruit kan duidelik vasgestel word dat die krake vorm waar die staalbewapening die beton verhoed het om

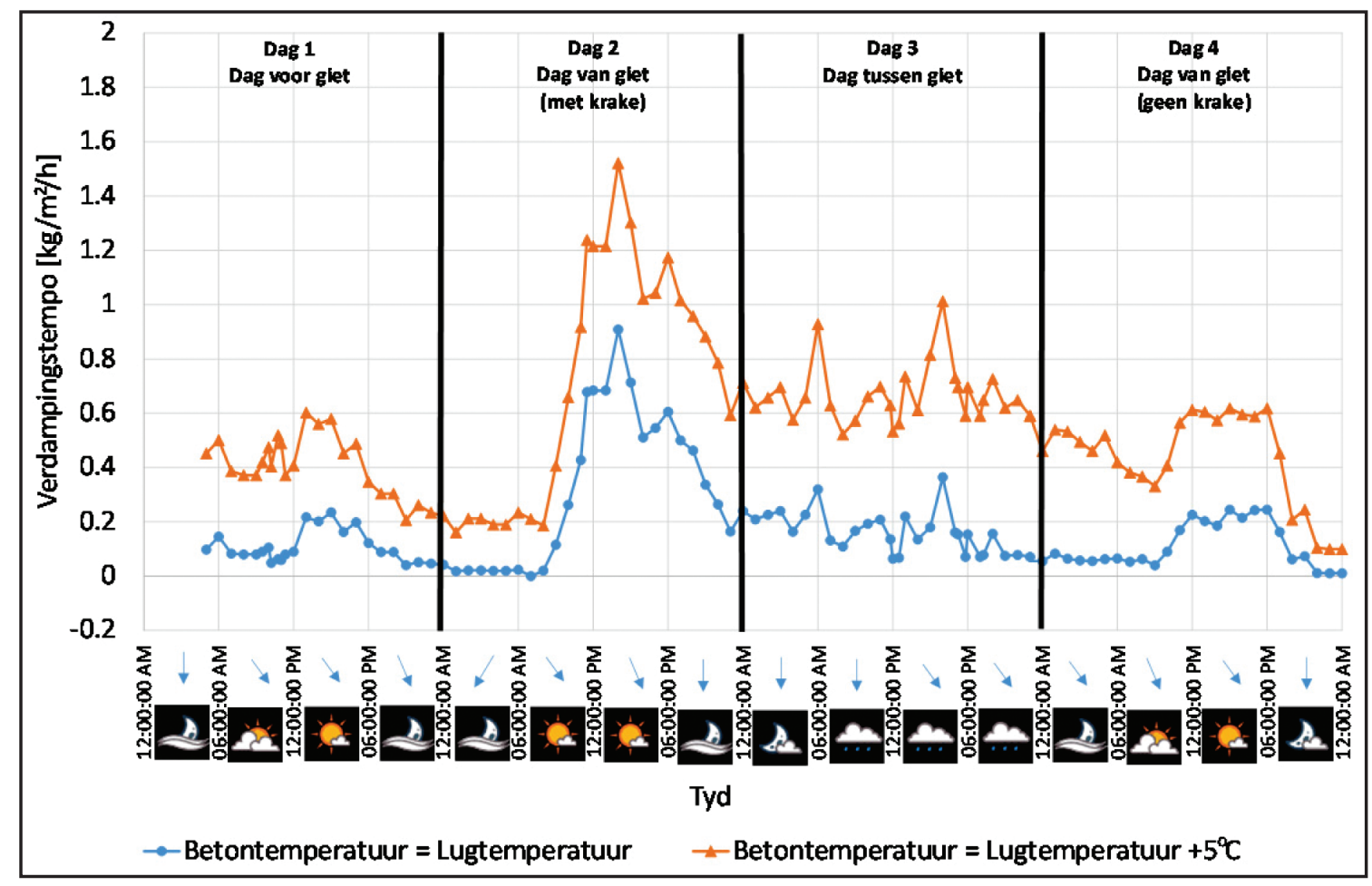

FIGUUR 6: Verdampingstempo's van Dae 1 tot 4.

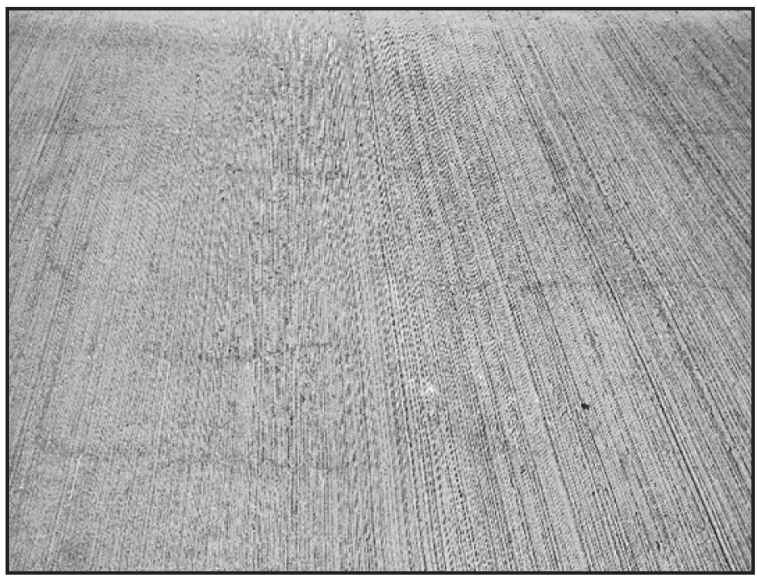

FIGUUR 7: Tipiese kraakpatrone waargeneem op die oppervlak van die betonpad.

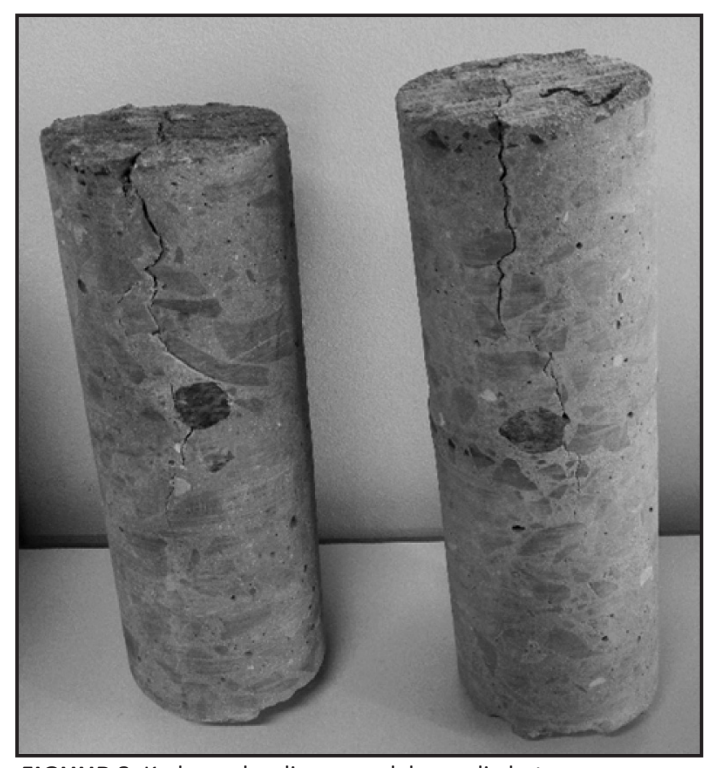

FIGUUR 8: Krake onder die oppervlak van die beton. 
vrylik te versak en te krimp. Hierdie is tipiese gedrag van plastiese beton waar die versakkingskrake vergroot word as gevolg van plastiese krimp.

\section{Verduideliking van kraakvorming}

Die hooffaktore wat ' $n$ invloed gehad het op die vorming van die krake in die gevalle studie is die klimaatstoestande en die vroeë vorming van plastiese versakkingskrake in die beton.

Die klimaatstoestande speel egter die grootste rol in die vorming van krake in die beton. Die skielike toename in die verdampingstempo van 0 tot $0.9 \mathrm{~kg} / \mathrm{m}^{2} / \mathrm{h}$ (beton temperatuur = lug temperatuur) of 0.2 tot $1.5 \mathrm{~kg} / \mathrm{m}^{2} / \mathrm{h}$ (beton temperatuur $5^{\circ} \mathrm{C}>$ as lug temperatuur) het veroorsaak dat die bloeiwater en later die poriewater uit die beton verdamp voordat die beton genoeg sterkte bereik het om weerstand te bied teen die spanning wat uitgeoefen word op die beton.

Alhoewel verskeie segmente van die pad met dieselfde mengsel gegiet was op dieselfde dag, het net sekere dele van die pad krake gewys. Die dele van die pad wat groot krake gevorm het, was gegiet tussen 10:59 en 12:10 soos getoon in Tabel 1. 'n Betonmengsel met 'n soortgelyke komposisie as in Tabel 2 (Combrinck, 2016) neem ongeveer 5 ure om te set en voldoende sterkte te bereik om plastiese krimp te weerstaan. Gegewe dat krake gedurende 'n 5-uur periode na giet verwag kan word, gee dit 'n periode van kraakvorming van ongeveer 11:00 tot 17:00. Die periode stem ooreen met die periode met die grootste verdampingstempo van 11:00 tot 18:00 soos getoon in Figuur 6. Die segmente wat dus gekraak het, was die segmente wat gegiet was in die middel van die dag toe die weersomstandighede hoë verdampingstempo's veroorsaak het.

Die hoë potensiaal vir plastiese versakkingskrake in die gevallestudie het ook bygedra tot die kraakvorming. Plastiese versakkingskrake vorm eerste en baie vroeg as gevolg van differensiële versakking van die beton om die staalbewapening. Die versakking vorm klein krake bo en onder die staalbewapening in die beton. Alhoewel die krake klein en byna onsigbaar is vir die blote oog en onder die oppervlak van die beton plaasvind, skep dit 'n swak area in die beton wat uitgebuit kan word deur ander meganismes wat lei tot krake. In die gevallestudie is die grootste deel van die krake wat waargeneem was plastiese krimp wat die klein versakkingskrake vergroot het. Die potensiaal vir plastiese versakkingskrake word ook verhoog aangesien die betondekking bo die staalbewapening varieer. In Figuur 8 kan gesien word dat die Y20 stawe nie op dieselfde diepte onder die beton gebind was nie en wissel tussen 85 en $109 \mathrm{~mm}$. Alhoewel dit binne die aanvaarbare toleransies is, sal gebiede met minder betondekking meer geneig wees om vroeër te kraak. Die vroeë vorming van plastiese versakkings krake vorm swak plekke in die beton wat beteken die plastiese krimpkrake kan vroeër begin en dus groter en vinniger vorm.

Veranderinge aan die mengselontwerp is ook ' $n$ faktor wat dikwels bydra tot ernstige plastiese krake, veral 'n hoër stofinhoud. Vir hierdie mengsel het die stofinhoud van die sand en klip gewissel en sou kon bydra tot die hoër potensiaal vir kraakvorming. Die waargenome krake het egter geleidelik begin, gevolg deur 'n skielike vergroting van die krake wat geleidelik afgeneem het met verloop van tyd. Die gedrag stem ooreen met die skielike verandering in verdampingstempo, terwyl die gevolge van 'n verandering in die mengsel slegs tussen individuele vragte waargeneem sou word en nie in halwe vragte soos in die geval van Vragmotors 5 en 10 nie.

\section{Gevolgtrekking}

Die vorming van plastiese krake in beton is 'n komplekse verskynsel met baie faktore wat dit kan beïnvloed. Hierdie faktore is tyd-afhanklik, asook onderling afhanklik van mekaar. Dit lei daartoe dat die krake nie noodwendig voorkom soos wat dit verwag word nie. Plastiese versakking is 'n volume verandering wat plaasvind ongeag van die klimaatstoestande, alhoewel die tempo waarteen plastiese versakking plaasvind wel afhanklik is van die klimaat. Die hoeveelheid, asook die tempo waarteen plastiese krimp plaasvind is afhanklik van die klimaat. Die gevolge van die volume verandering kan egter beter beheer word indien goeie kontrole, beplanning en konstruksiemetodes toegepas word. Deeglike kennis van die plastiese volume verandering kan lei tot beter besluitneming en metodes wat nie net die fisiese karakteristieke van die beton in ag neem nie, maar ook die klimaatsomstandighede.

Uit die gevallestudie kan afgelei word dat die kraakvorming 'n gevolg van beide plastiese versakking en krimp is, alhoewel plastiese krimp hoofsaaklik verantwoordelik is vir die groei van die kraak. Krake vorm as gevolg van skielike veranderinge in klimaatstoestande, veral in toestande waar die verdampingstempo naby of bo $1 \mathrm{~kg} /$ $\mathrm{m}^{2} / \mathrm{h}$ is. Daar moet dus voorsorg getref word wanneer beton gegiet word en goeie konstruksiemetodes moet gevolg word, behoorlike kuringsmetodes moet toegepas word en, waar moontlik, moet beton slegs gegiet word in weerstoestande wat nie 'n hoë potensiaal vir die vorming van plastiese krimpkrake het nie. 'n Deeglike kennis van die krake se gedrag en wat dit beïnvloed is nodig om dit te voorkom. Hierdie kennis kan die kwaliteit en duursaamheid van beton strukture verbeter.

\section{Erkennings}

Hierdie werk is ondersteun deur die SAAWK (Die SuidAfrikaanse Akademie vir Wetenskap en Kuns). Die werk is ook gedeeltelik ondersteun deur die Nasionale Navorsingstigting (NNS) van Suid-Afrika deur die Thuthuka 
befondsings instrument. Enige opinie, bevinding of aanbeveling in die artikel is die van die outeurs en die NNS aanvaar geen aanspreeklikheid hiervoor nie.

\section{Verwysings}

ACI 231R. 2010. Report on Early-Age Cracking: Causes, Measurement, and Mitigation. Farmington Hills: American Concrete Institute.

ACI 305. 1991. Hot weather concreting. ACI Journal. 74(8):317-32.

ASTM C232-20. 2020. Standard Test Method for Bleeding of Concrete. ASTM International, West Conshohocken, PA. 1-5.

Australian Pre-Mixed Concrete Association. 1995. Cracks in concrete due to plastic shrinkage and plastic settlement. Technical Bulletin 95/1.

Boshoff, W.P., Combrinck, R. 2013. Modelling the severity of plastic shrinkage cracking in concrete. Cement and Concrete Research. 48:34-9. https://doi. org/10.1016/j.cemconres.2013.02.003.

Carden, A.C., Ramey, G.E.1999. Weatherexposureanditseffectonbridgedeckcuring in Alabama. Practice Periodical on Structural Design and Construction. 4(4):139-46 Alabama. Practice Periodical on Structural Design and Constr
https://doi.org/10.1061/(ASCE)1084-0680(1999)4:4(139).

Cohen, M.D., Olek, J., Dolch, W.L. 1990. Mechanism of Plastic Shrinkage Cracking in Portland Cement and Portland Cement-Silica Fume Paste and Mortar. Cement and Concrete Research. 20(1):103-19. https://doi.org/10.1016/0008 8846(90)90121-D.

Concrete Society. 1978. Non-Structural Cracks in Concrete. Technical Report 22, Concrete Society Slough, England.

Combrinck, R. 2011. Plastic shrinkage cracking in conventional and low volume fibre reinforced concrete. MSc Thesis, Stellenbosch University, South Africa.

Combrinck, R. 2016. Cracking of plastic concrete on slab-like elements. PhD Dissertation, Stellenbosch University, South Africa.

Combrinck, R., Steyl, L., Boshoff, W.P. 2018a. Interaction between settlement and shrinkage cracking in plastic concrete. Construction and Building Materials. 185:1-11. https://doi.org/10.1016/j.conbuildmat.2018.07.028.

Combrinck, R., Steyl, L., Boshoff, W.P. 2018b. Influence of concrete depth and surface finishing on the cracking of plastic concrete. Construction and Building Materials. 175:621-8. https://doi.org/10.1016/j.conbuildmat.2018.04.225.

Dilley,A.C.(1968)OntheComputerCalculation of VaporPressureandSpecificHumidity Gradientsfrom Psychometric Data. Journal of Applied Meteorology. 7(4):717-19. https://doi.org/10.1175/1520-0450(1968)007<0717:OTCCOV>2.0.CO;2.

Ghourchian, S., Wyrzykowski, M., Baquerizo, L., Lura, P. 2018. Susceptibility of Portland cement and blended cement concretes to plastic shrinkage cracking. Cement and Concrete Composites. 85:44-55. https://doi.org/10.1016/j. cemconcomp.2017.10.002.

Harbeck, G.E., Kohler, M.A., Koberg, G.E., et al. 1954. Water loss investigations: Lake Hefner Studies, Technical Report. [Online], Available: https://scholar.google. $\mathrm{com} / \mathrm{sch}$ lar?q=others.+1954. Water+loss+investigations\%2C+Vol.+1\%2C+Lak e+Hefner+studies\%27\&btnG=\&hl=zh-CN\&as_sdt=0\%2C5.

Kohler, M.A., Nordenson, T.J., Fox, W.E. 1955. Evaporation from Pans and Lakes. Washington.

Kraai, P.P. 1985. Proposed Test to Determine the Cracking Potential Due To Drying Shrinkage of Concrete. Concrete Construction - World of Concrete. 30(9):775-8

Kwak, H.G., Ha, S., Weiss, W.J. 2010. Experimental and numerical quantification of plastic settlement in fresh cementitious systems. Journal of Materials in Civil Engineering. 22(10):951-66. https://doi.org/10.1061/(ASCE)MT.1943 5533.0000097.

Lerch, W. 1955. Hot Cement and Hot Weather Concrete Tests. Portland Cement Association. New York.

Lerch, W. 1957. Plastic Shrinkage. ACl Journal. (53):797-802. https://doi. org/10.14359/11555.
Menzel, C.A. 1952. Effect of Settlement of Concrete on Results of Pull-Out Bond Tests. Portland Cement Association. 41.

Menzel, C.A. 1954. Causes and Prevention of Crack Development in Plastic Concrete. in Portland Cement Association. 130-6.

Menzel, C.A., Woods, W.M. 1962. An investigation of bond, anchorage and related factors in reinforced concrete beams. Portland Cement Association. 42.

Moelich, G.M., Combrinck, R. 2020. A weather data analysis method to mitigate and prevent plastic shrinkage cracking. Construction and Building Materials. 253:119066. https://doi.org/10.1016/j.conbuildmat.2020.119066

Mills, G.A. 1975. A Comparison of Some Formulae for the Calculation of Saturation Vapor Pressure Over Water.

Murray, F. W. 1967. On the Computation of Saturation Vapor Pressure Journal of Applied Meteorology. 6(1). https://doi.org/10.1175/1520 0450(1967)006<0203:OTCOSV>2.0.CO;2.

Neville, A.M. 2011. Properties of concrete. 5th ed. Harlow England: Pearson Education Limited.

National Ready Mixed Concrete Association (NRMCA). 2006. Concrete in Practice: CIP 5.

Plastic Shrinkage Cracking. [Brochure]. Clobo.

Owens, G. 2009. Fulton's Concrete Technology. 9th ed. Midrand: Cement and Concrete Institute.

Powers, T.C. 1968. The Properties of Fresh Concrete. New York: John Wiley \& Sons, Inc.

Qi, C. 2003. Quantitative assessment of plastic shrinkage cracking and its effect on the corrosion of steel reinforcement. Indiana: Purdue University. Available at https://docs.lib.purdue.edu/dissertations/AAI3108400/.

Ravina, D., Shalon, R. 1968. Plastic Shrinkage Cracking. ACl Journal. (65):282-91. https://doi.org/10.14359/7473.

Turcry, P., Loukili, A. 2006. Evaluation of plastic shrinkage cracking of selfconsolidating concrete. ACl Materials Journal. 103(4):272-9. https://doi. consolidating concrete.
$\mathrm{org} / 10.14359 / 16611$.

Tetens, O. 1930. Uber einige meteorologische Begriffe Z. Geophys. 6:297-309.

Turton, C.D. 1978. Plastic Shrinkage of Concrete Current Practise Sheet, No 39. Concrete. 12.

SANS 1083. 2002. Aggregates from natural sources - Aggregates for concrete. Edition 2.1. Pretoria: Standards South Africa.

Slowik, V., Schmidt, M., Fritzsch, R. 2008. Capillary pressure in fresh cementbased materials and identification of the air entry value. Cement and Concrete Composites. 30(7):557-65. https://doi.org/10.1016/j. cemconcomp.2008.03.002

Soroka, I., Ravina, D. 1998. Hot weather concreting with admixtures. Cement and Concrete Composites. 20(2-3):129-36. https://doi.org/10.1016/S0958and Concrete Compo

Uno, P.J. 1998. Plastic shrinkage cracking and evaporation formulas. ACI Materials Journal. 95(4):365-75. https://doi.org/10.14359/379.

Van Zyl, J.E. 2021. The influence of temperature on the cracking of plastic concrete. M.Eng Thesis. University of Stellenbosch.

Weyers, R.E., Conway, J.C., Cady, P.D. 1982. Photoelastic analysis of rigid inclusions in fresh concrete. Cement and Concrete Research. 12(4):475-84. https://doi.org/10.1016/0008-8846(82)90062-X.

Wittmann, F.H. 1976. On the action of capillary pressure in fresh concrete. Cement and Concrete Research. 6(1):49-56. https://doi.org/10.1016/00088846(76)90050-8.

Wongtanakitcharoen, T. 2005. Effect of Randomly Distributed Fibres on Plastic Shrinkage Cracking of Cement Composites. Michigan: The University of Michigan. (PHD-thesis). 